\title{
Influence of Sepiolite's Incorporation in Diet on the Performance and Welfare of Turkey Reared on Two Types of Litter
}

\begin{abstract}
Naceur M'hamdi' ${ }^{*}$, Manel Ben Larbi ${ }^{2}$, Aziza Raach Moujahed ${ }^{1}$, Ameni Askri ${ }^{1}$, Cyrine Darej ${ }^{1}$, Khouloud Boukhali ${ }^{1}$, Nadia ben Braiek ${ }^{3}$, Hajer M'hamdi' $^{4}$, Kaouther Mrabet ${ }^{3}$ and Abdallah Jebeli ${ }^{5}$
\end{abstract}

${ }^{1}$ National Agronomic Institute of Tunisia, University of Carthage, Tunisia

${ }^{2}$ Higher School of Agriculture of Mateur, Bizerte, Tunisia

${ }^{3}$ Ministery of Agriculture. CRDA Sousse, Tunisia

${ }^{4}$ Ministery of Agriculture CRDA Ben Arous, Tunisia

${ }^{5}$ Société de nutrition animale (SNA), Tunisia

Submission: May 09, 2019; Published: June 19, 2019

"Corresponding author: Naceur M'hamdi, National Agronomic Institute of Tunisia, University of Carthage, Tunisia

\begin{abstract}
This study was carried out to determine the influence of adding sepiolite to the diet on performances of turkey. A total of 960 male broilers of the Hybrid strain were used. The animals received a DFIE starter food crumbled from day 1 to day 28, a growth food1 DF2G granulated from day 29 to day 42, a growth food 2 DF2-3G granulated from day 43 to day 63, a growth food. 3 DF3G pellet day 64 to day 84, and a DF4G finish growth food from day 85 to slaughter (day 119). The chicks have a starting average weight of about 56.8 g. Overall the rearing periods, the standard feed gave the best results in terms of average weight $(56.9 \mathrm{~g})$ versus $(13334.33 \mathrm{~g})$, respectively, during periods 1 and 10 . The T1 food improved the consumption index and the T2 showed no significant effect. On the other hand, there were no significant differences between the three ST, T1 and T2 treatments and between the two litter types $\mathrm{C}$ and PB for the mortality rate. Although no significant difference between the two types of litter (C, $\mathrm{PB}$ ), the wood chips have the best results in terms of improvement of performance and reduction of poultry diseases.
\end{abstract}

Keywords: Turkey flesh; Hybrid strain; Sepiolite; Zootechnical performance; Litter

Abbreviations: ADG: Average Daily Gain; IG: Ingested Feed; LW: Live Weight; AW: Average Weights CI: Consumption Index; TM: Mortality Rate; HR: Relative Humidity

\section{Introduction}

Antimicrobial compounds are commonly included in poultry diets for promoting of growth and control of diseases. Feeds containing no chemical additives are increasingly used in poultry nutrition. Therefore, antibiotic growth promoters were discredited by consumers as well as by scientists (Humphrey et al., 2002). Many scientists searched for alternatives to antibiotic growth promoters [1,2]. Traditionally, clays have been incorporated in diets $(10 \pm 20 \mathrm{~g} / \mathrm{kg})$ as a technological additive (lubricant) to improve feed manufacture [3]. Sepiolite is a feed additive (E-562) used as a binder and anti-caking agent up to $2 \%$ in all feeds for all animal species [4]. Sepiolite has effects on the productive performance of broilers and laying hens $[5,6]$ by affecting on the physical and kinetic properties of digesta. Sepiolite may replace growth factors, antibiotics and anticoccidials in poultry diets as therapeutic agents [6-8]. Eser et al. [9] reported that $1 \%$ sepiolite in broiler diets increased body weight gain and reduced the relative weight of abdominal fat and the levels of serum cholesterol and triglyceride. Fernandez et al. [10] stated the effects of sepiolite on bone characteristics in broiler. The main objective of this study was to evaluate the effects sepiolites' incorporation on the performance and welfare of turkey reared on two types of litter.

\section{Material and Methods}

\section{Feed Formulation, Broilers and Experimental Design}

The trial protocol was conducted during 119 days from 29 December 2015 to 26 April 2016, in the animal nutrition company (SNA) in its experimental station "Ben Khelifa" spread over a perimeter of 3 ha. A total of 960 one-day-old turkeys from the SABA company hatchery were used in this study. Poultry received diets with high-energy concentrations in the order of $2850,2920,3025,3100$ and $3200 \mathrm{kcal}$ of metabolizable energy 
for foods, respectively, starter, growth, fattening and finishing. The three tested diets are ST: standard diet (control), T1: diet with sepiolite in top (1\% of EXAL sepiolite) and T2: diet with sepiolite in reformulation obtained by the replacement of $1 \%$ of the quantity but introduced in the standard formula by $1 \%$ of EXAL sepiolite. Groups of 40 chicks were divided into separate lots randomly selected for one of the experimental treatments. Throughout the trial, commercial management procedures were employed, and ambient temperature was controlled. Natural and artificial light was provided on a basis of $23 \mathrm{~h}$ for the first 2 days, $16 \mathrm{~h}$ from day 3 to day 14, $21 \mathrm{~h}$ from day 15 to the slaughter days. All birds were vaccinated against Newcastle disease, Infectious Bronchitis and Gumboro during the second week of their life.

\section{Measured parameters and statistical analysis}

The measured parameters are: live weight (LW) at different dates (LW28, LW42, LW56, LW70, LW84, LW98, LW112, LW119), average weights (AW): (AW1-14, AW14-28; AW28-42, AW42-56, AW56-70, AW70-84, AW84-98, AW98-112, AW112-119, average daily gain (ADG): (ADG1-14, ADG14-28, ADG28-42, ADG42-56, ADG56-70, ADG70-84, ADG84-98, ADG98-112, ADG112-119 and ADG1-119), the amount of food ingested (IQ), the consumption index (CI), the mortality rate (TM), the relative humidity of litter (HR) and the health status of turkeys. The data was analyzed as a $2 \times 3$ factorial randomized complete block design to determine main effects and interactions, three feed forms (ST, T1 and T2) and two litter types (C, PB). All data were analyzed using PROC GLM of the SAS program [11] (Version 9.1, SAS Institute Inc., Cary, $\mathrm{NC}$ ). Differences were considered significant at $\mathrm{P}<0.05$ and the differences between means were separated by least significant difference

\section{Results and discussions}

\section{Average Weight}

Table 1: variation of average weight during trial.

\begin{tabular}{|c|c|c|c|}
\hline Period & Average weight (g) & Standard error & Pr $>\mathbf{t}$ \\
\hline P1 & 56.9229 & 89.883 & 0.5273 \\
\hline P10 & 13334.33 & 89.883 & $<.0001$ \\
\hline P2 & 318.9394 & 92.346 & 0.0007 \\
\hline P3 & 979.3542 & 89.883 & $<.0001$ \\
\hline P4 & 1986.708 & 89.883 & $<.0001$ \\
\hline P5 & 3640.583 & 89.883 & $<.0001$ \\
\hline P6 & 5577.708 & 89.883 & $<.0001$ \\
\hline P7 & 7526.896 & 89.883 & $<.0001$ \\
\hline P8 & 10076 & 89.883 & $<.0001$ \\
\hline P9 & 12356 & 89.883 & $<.0001$ \\
\hline
\end{tabular}

The average live weight of turkey broilers is similar for all diets. Indeed, the initial weight of $56.8 \mathrm{~g}$ to reach a live weight of $13334.33 \mathrm{~g}$ at period 10 (Table 1 ). Live weight at day 0 of chicks belonging to the three treatments was statistically identical $(\mathrm{P}>0.05)$. This proves that the lots were homogenous and did not exhibit weight variability. However, analysis of the variance showed a significant effect $(\mathrm{p}<0.001)$ of the diet on live weight (Figure 1). Several authors admit the same results. Castaing [12] showed that the incorporation of $1 \%$ sepiolite into the flesh turkey feed leads to an improvement in weight: $5.7 \%$ at 6 weeks, $3.9 \%$ at 9 weeks and $1.2 \%$ at the age of slaughter. Tolsa Group [13] has shown that the addition of a higher level (2\%) of EXAL leads to an improvement of $3.23 \%$ in total average weight (11.701 kg vs $12.092 \mathrm{~kg}$ ) against the control diet and $2.69 \%$ against other clays.

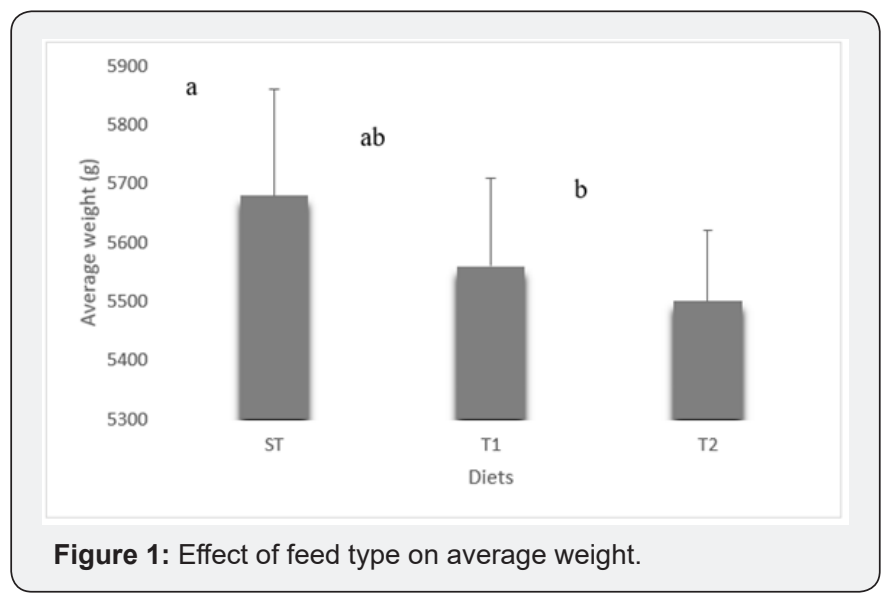

In fact, the subjects who received the standard control diet (ST) had significantly greater weights than the groups receiving the treatments (T1) and (T2) ( $\mathrm{P}<0.05)$ with respective average weights, $5685.45 ; 5569.51$ and 5501.06 g. On the other hand, during the first period (14 days) we recorded average weights of 56.91 and $57.1 \mathrm{~g}$ for treatments $\mathrm{T} 1$ and $\mathrm{T} 2$, respectively, versus $56.92 \mathrm{~g}$ for (ST). Whereas during the last week of rearing, the animals fed the regimes with sepiolite in Top, (T1) and reformulation (T2) respectively have average weights of 13334.33 and $9900.42 \mathrm{~g}$ against $14803.43 \mathrm{~g}$ for the batch receiving the standard food control. This was demonstrated by statistical analysis which revealed a significant difference $(P=0.0298)$ between these three treatments during the study period. This may be due to an interaction between the energy concentration and the presence of EXAL. With the incorporation of 1\% of EXAL, growth tends to be $1.03 \%$ lower with the least energy-dense food $3100 \mathrm{kcal}$ (T1) and $1.64 \%$ with the more energy-dense food. The synergy between the diets and the period has no significant effect on the evolution of turkey average weight. However, we found no effect of litter types (C, PB) on weight $(P=0.3913)$.

\section{Average Daily Gain (ADG)}

Results shows the evolution of ADG, depending only on the period effect. It is noted that this parameter changes significantly from $60.34 \%$ ( $18.71 \mathrm{vs} 47.19 \mathrm{~g} / \mathrm{d}$ ) in start-up period (weeks $1,2,3,4)$, to $47.99 \%$ ( 138.36 vs $71.95 \mathrm{~g} / \mathrm{d}$ ) during the growing season, $23.53 \%$ (182.07 vs. $139.22 \mathrm{~g} /$ day) during the fattening period then decreases by $16.52 \%$ (162.85 vs 139.76 vs 3.29 $\mathrm{g} / \mathrm{d}$ ) during the finishing period. This coincides with the results obtained by Tolsa Group [13], which has shown a significant increase in turkey weight gain during all breeding periods. 
The analysis of the variance revealed no significant difference between the three diets (ST, T1 and T2), and despite the absence of significant effect on the evolution of weight gain $(\mathrm{P}>0.05)$ during the whole control period (ST) seems to have a slightly higher weight gain compared to treatments with sepiolite (T1, T2) (Table2).

Table 2: Effects of diet and litter on average daily gain.

\begin{tabular}{|c|c|}
\hline \multicolumn{2}{|c|}{ ADG (g) } \\
\hline \multicolumn{2}{|c|}{ Feed } \\
\hline T1 & $111,99 \pm 0,027 \mathrm{a}$ \\
\hline T2 & $111.46 \pm 0,022 \mathrm{a}$ \\
\hline ST & $112.49 \pm 0,023 \mathrm{a}$ \\
\hline \multicolumn{2}{|c|}{ Litter } \\
\hline PB & $111.515 \pm 0,21 \mathrm{a}$ \\
\hline C & $112.769 \pm 0,25 \mathrm{a}$ \\
\hline
\end{tabular}

In addition, litter types (C, PB) have no significant effect on the evolution of ADG during the four rearing phases $(P=0.21)$ (Table 2). In the same context, Ritez [14], in studying the impacts of strawberries and straw on the zootechnical performance of turkeys, showed that chopped straws and wood chips have no significant effect on weight gain. Analysis of variance showed the absence of any significant effect of the food-litter interaction (Table 3). But it appears that the ADG recorded for the control (ST) are slightly improved on straw litter in corks compared to the cuttings (115.35 vs. $109.22 \mathrm{~g} / \mathrm{d}$ ) whereas for the treatments with sepiolite (T1, T2), ADG are better for litter animals respectively, 115.35 (T1, C) vs $113.5 \mathrm{~g} / \mathrm{d}$ (T1, PB) and 113.72 (T2, C) vs 111.28 g/d (T2, PB).

Table 3: Effect of the interaction feed-litter on average daily gain.

\begin{tabular}{|c|c|c|}
\hline Litter & Diet & ADG (g) \\
\hline C & ST & $109.22 \pm 0,364$ \\
\hline C & T1 & $115.35 \pm 0,370$ \\
\hline C & T2 & $113.72 \pm 0,367$ \\
\hline PB & ST & $115.75 \pm 0,374$ \\
\hline PB & T1 & - \\
\hline
\end{tabular}

\section{Ingested Feed (IF)}

The amount of food ingested varies significantly with changes in turkey age $(P<0.0001)$. Indeed, we recorded significant improvements towards the third period of $1.18 \%$ ( 22.95 vs $35.91 \mathrm{~g}$ ), the sixth period of 5.94\% (69.5 vs134.26) g and towards the ninth period of $5.83 \%$ (167.33 vs $230.94 \mathrm{~g}$ ). The daily consumption of animals is in line with the application of the energy ration plan. The difference in energy concentration of 200 kcal between foods (ST and T2) leads to a significant difference ( $\mathrm{P}<0.001)$ of average consumption greater than 1.15\%, $(124.83$ g / floor / period vs 120.65 g / floor / period). Foods with sepiolite in top (T1) allowed to consume a quantity lower than the control of $1.9 \%$ (124.83 g / office / period vs $117.74 \mathrm{~g} /$ office / period). Knowing that the same daily energy intake was assured with all foods. These results confirm those obtained previously under similar conditions $[12,15]$. The litter had no effect on the quantity of food ingested, but it showed, in synergy with the different diets (ST, T1, T2), significant differences $(\mathrm{P}<0.05)$. In fact, feed consumption (ST and T2) by turkeys reared on straw corks improved by about $0.7 \%$ and $2.42 \%$, respectively. Only the regimen with sepiolite in top (T1) shows an improvement on wood chips of $2.16 \%$. In the same context, many studies admitted the lack of significant litter effect on performance while others showed that the wood chips $[12,15]$. In contrast, others studies showed the significant effect of both litter types (C, PB) on flesh poultry performance $[13,16]$.

\section{Consumption Indice}

For the evolution of food consumption per week, we observe a significant increase $(\mathrm{P}<0.001)$ in the consumption index over all rearing periods. These fluctuations in C-teeth can be explained by the presence of a latency time necessary for the turkey to adapt after each food transition (starter food. growth food. fattening feed and finishing food). The type of food has no significant effect on the consumption index $(P=0.22)$. Besides, there is no significant difference between the three diets (ST. T1. $\mathrm{T} 2$ ). The incorporation of $1 \%$ sepiolite in top or reformulation into the fleshed turkey feed has no significant effect $(\mathrm{P}>0.005)$ on palatability (Table 4). On the other hand, there is a slight nonsignificant increase $(P=0.22)$ in the consumption index for the lots receiving the control diet (ST). (2.47) against the batches receiving the $\mathrm{T} 1$ and $\mathrm{T} 2$ regimens which respectively $(2.377$ and 2.432)

Table 4: Effect of feed type on consumption indice.

\begin{tabular}{|c|c|}
\hline Diet & Consumption indice \\
\hline ST & $2.470 \pm 0.226 \mathrm{a}$ \\
\hline T1 & $2.377 \pm 0.228 \mathrm{a}$ \\
\hline T2 & $2.432 \pm 0.226 \mathrm{a}$ \\
\hline
\end{tabular}

Our results disagree with those of Castaing et al. [17]. The incorporation of $2 \%$ Sepiolite in turkey food significantly improves the consumption index with a rate of $4.3 \%$. This can be explained by the fact that the addition of sepiolite at a rate of $1 \%$ in the diet can never pass without leaving effects on the feeding behavior of the animals. In fact. the food that contains sepiolite is often characterized by a slightly increased hardness compared to the control food and its ability to slow food transit. Besides the bibliographies provide the best feed efficiency is guaranteed for the most energy intake which coincides in our case. The diet with sepiolite in top (ST) is in cumulates on all breeding periods more consumed. The litter type did not show any significant effect $(\mathrm{P}=$ 0.082 ) on the turkey consumption index.

\section{Mortality Rate}

Mortalities are recorded every day at each level during the breeding period and at the end of the experiment collected per week. During all the breeding periods, mortality rate varies significantly $(p<0.001)$. Indeed, during the first phase of growth that the mortality rate is highest during the 17 weeks exceeding 6, 04\% (Figure 2). Mortality was recorded in the first few days 
after litter renewal. especially in straw and cork flooring. The analysis of cadavers showed that this increase in mortality due mainly due to litter consumption. The diet has no significant impact on the mortality rate $(\mathrm{P}>0.05)$ (Table 5$)$. The litter has not a significant impact on the mortality rate $(\mathrm{P}=0.34)$. This is confirmed by previous studies that showed that litter has no direct effect on turkey mortality rate although it may be origin of certain pathologies $[18,19]$.

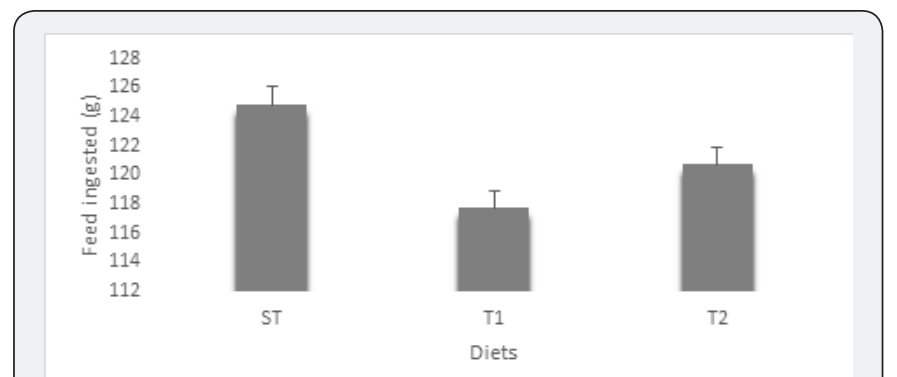

Figure 2: Variation of ingested food with diet types

Table 5: Effect of diet and litter types on mortality rate of birds.

\begin{tabular}{|c|c|}
\hline \multicolumn{2}{|c|}{ Mortality (\%) } \\
\hline \multicolumn{2}{|c|}{ Diet } \\
\hline ST & $1.11 \pm 0.420^{\mathrm{a}}$ \\
\hline T1 & $1.92 \pm 0.424^{\mathrm{a}}$ \\
\hline T2 & $1.49 \pm 0.424^{\mathrm{a}}$ \\
\hline \multicolumn{2}{|c|}{ Litter } \\
\hline PB & $1.50 \pm 0.34^{\mathrm{a}}$ \\
\hline C & $1.51 \pm 0.34^{\mathrm{a}}$ \\
\hline
\end{tabular}

\section{Health Status of Birds}

During breeding period (19 weeks), the bulbs at the keel bone level changes significantly $(\mathrm{P}<0.001)$ with the turkey age $(5 \%)$, this can be explained by the accumulation of waste and droppings and the lowering of building hygiene status and the higher of litter moisture level. Birds reared on wood chunks had significantly lower $(\mathrm{P}<0.001)$ keel bone infections and ampoules $(0.53 \%)$ than those raised on straws. It is therefore the cutters that seem to allow the best results in terms of slowing down the evolution of the keel bulbs. These results confirm the positive effects of the use of the cuttings on the performances of birds [14], notably by decreasing litter crusting [16].

\section{Conclusion}

This study aims to use food additives and litter in poultry farming. Our results showed the effectiveness of additives and bedding as a promising approach to poultry farming to improve feed quality, growth performance and bird health status. In this study, we used sepiolite as a technological additive and straw straw as litter. To this end, three diets were studied on a large turkey population on two types of bedding to determine their effectiveness from the first day to age at slaughter. The ST standard control diet allowed the highest zootechnical performance in terms of average weight and average weight gain. The diet with sepiolite in top T1 allowed the best consumption index and the ration with sepiolite in reformulation has no improvement effect $(\mathrm{P}>0.01)$. The two regimens with sepiolite did not show any effects on the mortality rate for the different litter types. For the litter, the cuttings have the best results in terms of slowing of the evolution of the cornet bulbs. While, it does not show any significantly effect on the buttons of the breast, the scratches and the lesions of foot pad. Straw plugs have no effect on zootechnical performance and on health status during the four rearing phases.

\section{References}

1. Langhout P (2000) New additives for broiler chickens. World PoultryElsevier 16(3): 22-27.

2. Kamel C (2001) Tracing modes of action and the roles of plant extracts in non-ruminants. In Recent advances in animal nutrition. Garnsworthy PC, Wiseman J (Eds.), Nottingham University Press, Nottingham, pp. 135-150.

3. Angulo E, Brufau J, Esteve-Garcia E (1995) Effect of sepiolite on pellet durability in feeds differing in fat and fibre content. Anim Feed Sci Technol 53: 233-241.

4. https://www.efsa.europa.eu/en/topics/topic/campylobacter.

5. Ouhida I, Perez JF, Gasa J, Puchal F (2000) Enzymes ( $\beta$-glucanase and arabinoxylanase) and/or sepiolite supplementation and the nutritive value of maize-barley wheat-based diets for broiler chickens. Br Poult Sci 41: 617-624

6. Tortuero F Fernandez Gonzalez E, Martin ML (1992) Effects of dietary sepiolite on the growth, visceral measurements and food passage in chickens. Arch. Zootec. 41: 209-217.

7. Ayed MH, Zghal I, Rekik B (2008). Effect of sepiolite supplementation on broiler growth performances and carcass yield. Proc. West Sect Am Soc Anim Sci 59: 169-172.

8. Viseras C and Lopez-Galindo A (1999) Pharmaceutical application of some Spanish clays (sepiolite, palygorskite, bentonite): some preformulation studies Appl Clay Sci 14: 69-82.

9. Eser H, Yalçın S, Yalçın S, Şehu A (2012) Effects of sepiolite usage in broiler diets on performance, carcass traits and some blood parameters. Kafkas Univ.Vet. Fak. Derg 18: 313-318.

10. Fernandez E, Tortuero F, Martin L (1994) The effects of different levels of dietary sepiolite on tibial dyschondroplasia in chickens. Arch. Geflügelk 58: 171-175.

11. Statistical analysis system (2002) SAS user's guide. Version 9.0. Cary, SAS. Institute.

12. Castaing J (1989) Effet de l'inclusion de 2\% de Sepiolite "EXAL" clans les aliments á deux niveaux énergétiques présentés en granulés pour porcelets et porcs charcutiers. Journées de la Recherche Porcine en France, 21: 51-58.

13. Tolsa group (2002) EXAL T: Optimizing binder granulation additive feed and the yield of the plant.

14. Ritz CW, Fairchild BD, Lacy MP (2004) Implications of ammonia production and emissions from commercial poultry facilities: A review. Journal of Applied Poultry Research 13: 684-692.

15. Parisini SL, Panciroli A, Coppa C (1993) Effetţi della sustituzione con sepiolite di parte de la mangime nelfalimentazione del suino pesante. Atţi10 et dquo, Congresso Nazional ASPA pp. 459-464. 
16. Tasistro AS, Kissel DE, Bush PB (2004) Spatial variability of broiler litter composition in a chicken house. Journal of applied poultry research 13: pp 29-43.

17. Castaing J, Larroudé P, Peyhorgue A, Hamelin C, Maaroufi C (2003) incidence de deux niveaux d'apports en vitamines sur les performances du poulet de chair. Cinquièmes Journées de la Recherche Avicole, Tours, 26 et 27 mars.
18. Uso de las arcillas en alimentación animal. In: CURSO DE ESPECIALIZACIÓN, (1998), Barcelona. Avances em nutrición y alimentación animal. Barcelona Fundación Española para el Desarrollo de la Nutrición Animal, 14: 141-158.

19. Folegatti E, Sirri F, Meluzzi A, Toscani T (2006) Prevalence of foot pad lesions and carcass injuries as indicators of broiler welfare conditions in Italy, In $12^{\text {th }}$ European Poultry Conference, Verona, Italy, pp. 303-307.

\section{Your next submission with Juniper Publishers will reach you the below assets}

- Quality Editorial service

- Swift Peer Review

- Reprints availability

- E-prints Service

- Manuscript Podcast for convenient understanding

- Global attainment for your research

- Manuscript accessibility in different formats ( Pdf, E-pub, Full Text, Audio)

- Unceasing customer service

Track the below URL for one-step submission https://juniperpublishers.com/online-submission.php 